\title{
The Research Review and Prospect of Compromise Effect
}

\author{
Xinqian Li \\ School of Management, Jinan University, Guangzhou, China \\ Email: lixinqian@foxmail.com
}

How to cite this paper: Li, X. Q. (2020). The Research Review and Prospect of Compromise Effect. Open Journal of Social Sciences, 8, 207-222.

https://doi.org/10.4236/jss.2020.84015

Received: March 19, 2020

Accepted: April 12, 2020

Published: April 15, 2020

Copyright $\odot 2020$ by author(s) and Scientific Research Publishing Inc. This work is licensed under the Creative Commons Attribution International License (CC BY 4.0).

http://creativecommons.org/licenses/by/4.0/ (c) (i) Open Access

\begin{abstract}
The rational choice theory holds that consumers will always choose the product with the maximum utility, while the context effect emphasizes that consumers' choice will change with the change of the situation, and the rational decision is not always made. As a model of context effect, the compromise effect points out that when an extreme option is added to the selection set, the original option will become a compromise option and become more attractive. On the basis of a systematic review of the literature related to the compromise effect, this paper summarizes and prospects the compromise effect. First of all, this paper introduces the concept of the compromise effect, and the similarities and differences between the compromise effect, the context effect and the attraction effect. Secondly, this paper discusses the formation mechanism of compromise effect from the perspective of reason seeking, loss aversion and rational decision-making. Third, based on the literature review, this paper discusses the impact factors of the compromise effect. Finally, this paper puts forward the enlightenment of the compromise effect to the marketing practice, and points out the future research direction.
\end{abstract}

\section{Keywords}

Compromise Effect, Context Effect, Consumer Decision

\section{Introduction}

Life is full of choices. Single-attribute decisions, such as choosing the lowest-rent apartment in a selection set, are always simple. However, most of the decisions in reality are based on multiple attributes, and the decision-making process is rather complicated, for example, to choose an apartment, both the rental price and the location of the apartment from the company should be considered. At this point, consumers are easily trapped in a choice dilemma: should they choose 
a lower rent? Or should it be closer to work? Faced with the same choice problem, different consumers will have different choices.

Traditional rational choice theory holds that consumers will follow the principle of value maximization and will choose the goods with value maximization under any circumstances (He, 2005). However, practice has proved that rational choice theory is not always applicable due to the complexity of decision-making situation. For example, in the case of renting an apartment just mentioned, if you choose the two options of apartment $A$ and apartment $B$, the rent of apartment $B$ is lower than that of apartment $A$, while apartment $A$ is closer to the company than that of apartment $B$, which option should you choose? If apartment $C$ (which has a lower rent than $B$, but is further away from the company than B) is added in the selection set, apartment B will become the compromise option. When apartment B becomes a compromise option, its probability of being chosen is increased, and this is the compromise effect. The compromise effect subverts the traditional rational choice theory, proving that consumers' choice is not fixed, and the addition of a new extreme term will increase consumers' preference for the compromise option (Simonson, 1989).

Why the compromise effect? The formation mechanism of the compromise effect is mainly discussed from the perspective of seeking reasons, loss avoidance and rational decision. In addition, the academic community has also studied the influencing factors of the compromise effect, which mainly include consumer factors, product factors, selection factors and decision-making environment factors. On the basis of systematic review and analysis of previous studies, this paper introduces the concept development of the compromise effect, summarizes the formation mechanism and influencing factors of the compromise effect, and discusses the practical enlightenment of the compromise effect and the possible research direction in the future.

\section{The Concept of Compromise Effect}

\subsection{Context Effect and Compromise Effect}

Based on the "rational economic man" hypothesis, the traditional rational choice theory holds that consumers will follow the principle of value maximization. At the same time, the rational choice theory holds that consumers' measurement of the utility of goods is independent of the standby choice set in which the goods are located. In any case, consumers will choose the goods or commodity combinations that satisfy the value maximization (He, 2005). But in practice, consumers face more complex decision-making situations. For example, in multi-attribute decision making, various attributes often cannot be compared with each other, and it is difficult for consumers to consider the relationship between multiple indicators, which makes it difficult for them to make rational decisions. Therefore, rational choice theory is considered to be inapplicable in many practical situations, and consumers' choice results are often related to their historical choice situation and the currently available set of goods, which is the context ef- 
fect (Tversky \& Simonson, 1993).

According to the context effect theory, when consumers evaluate the target option, they not only consider the absolute level of the target option attribute, but also examine the relative position of the target option in the selection set with other options (Tversky \& Simonson, 1993). The context effect emphasizes that consumers' choice is not unchanged, but changes with the change of the situation, which subverts the traditional rational choice theory (Guo, 2013). In the study of context effect, scholars focus on attraction effect, compromise effect, substitution effect and phantom effect.

The compromise effect is one of the models of context effect, first proposed by Simonson in 1989. Simonson (1989) pointed out that the compromise effect means that in a situation, adding a new option makes the original option more attractive, because the original option has become a compromise option among the existing three options. In the rational choice model, the law principle states that adding a new option to the set of options does not increase the selection probability of any initial option (Dhar \& Glazer, 1996). The compromise effect violates this principle by reflecting that adding a third option increases the likelihood that the target option will be selected.

\subsection{Attraction Effect and Compromise Effect}

Both the attraction effect and the compromise effect belong to the context effect. Therefore, by identifying the similarities and differences between the attraction effect and the compromise effect, the concept of the compromise effect can be better understood.

In 1982, Huber et al. (1982) discovered the existence of the compromise effect in the process of studying the attraction effect, but only regarded it as a special attraction effect. In 1983, Huber \& Puto (1983) first proposed the concept of "compromise" as a special attraction effect without "elbow". It was not until 1989 that Simonson distinguished the compromise effect from the attraction effect and clarified the concept of the compromise effect.

The similarity between the attraction effect and the compromise effect is that they both reflect that adding a new choice to the existing selection set will have an impact on the individual's original selection preference. However, the attraction effect emphasizes that an asymmetric dominant option is added, which makes a certain option in the original selection set more attractive and thus increases the probability of being selected (Zhang et al., 2011). The compromise effect emphasizes that by adding an extreme option, an option in the original selection set becomes a compromise option, thus increasing the selection preference for the compromise option (Dhar \& Glazer, 1996).

As shown in Figure 1, product A and product B exist in the original product set, which have advantages in attribute 2 and attribute 1 , respectively. When asymmetric dominant option $\mathrm{C}$ is added, the original product is integrated into the asymmetric dominant product set, forming the attraction effect relationship. 
In the aspect of attribute 1 , target product $B$ is superior to product $C$. In attribute 2 , target product $B$ is also superior to product $C$. Due to the addition of asymmetric dominant option $\mathrm{C}$, the target product $\mathrm{B}$ becomes more attractive, thus increasing the probability of consumers choosing product $\mathrm{B}$.

As shown in Figure 2, product A and product B exist in the original product set, which have advantages in attribute 2 and attribute 1 , respectively. When extreme option $\mathrm{C}$ is added, the target product $\mathrm{B}$ becomes the compromise option, thus increasing the selection preference for the compromise option, resulting in the compromise effect.

\section{The Formation Mechanism of the Compromise Effect}

Why the compromise effect? Is it an intuitive decision that consumers make to save thinking when faced with complex decision situations? The answer is not.

\section{Attribute2}

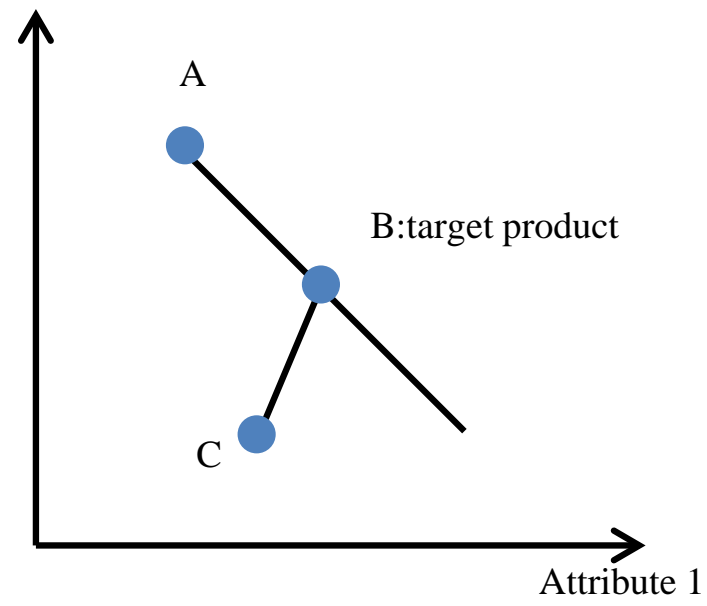

Figure 1. Schematic diagram of attraction effect.

\section{Attribute 2}

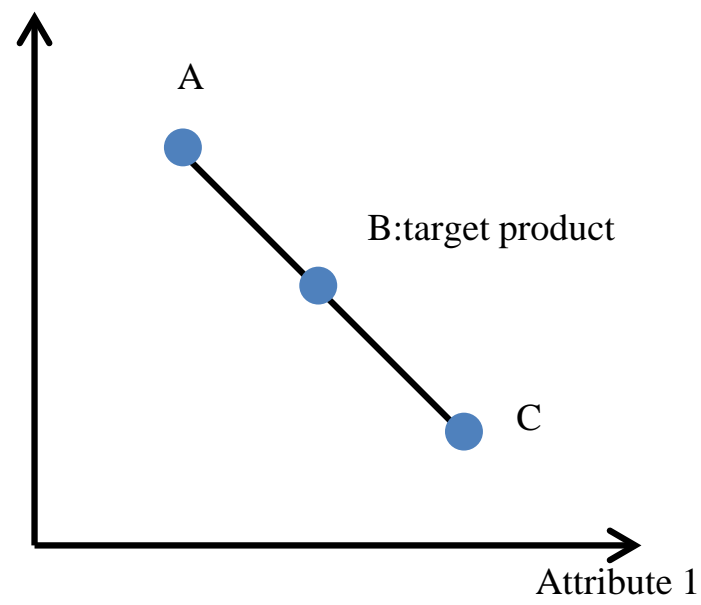

Figure 2. Schematic diagram of compromise effect. 
Simonson (1989) used the method of thinking aloud to track the decision-making process of consumers and found that those subjects who chose the compromise option had longer decision-making records than those who chose the extreme option. Lichters and other scholars (2016) manipulated the subjects' serotonin levels by controlling whether the drink given to the subjects contained tryptophan. Participants who did not drink tryptophan-containing beverages had lower levels of the neurotransmitter serotonin in their brains and less availability of cognitive resources than those who drank tryptophan-containing beverages. The results suggest that reduced serotonin levels weaken the compromise effect, providing neurobiological evidence that the compromise effect is the result of a deliberate process rather than an intuitive decision.

So what causes the compromise effect, and how does it work? Different scholars put forward different views according to different perspectives.

\subsection{The Perspective of Seeking Reasons}

Simonson (1989) believed that when consumers were faced with products with different attributes and unable to make a choice, the compromise choice of two attributes could reduce the conflict and dissonance caused by the choice and provide a valid reason for the choice. This compromise effect is reinforced when consumers expect to justify their choices to others or expect to be positively evaluated by others.

\subsection{The Perspective of Loss Aversion}

Selection usually involves two kinds of uncertainty, one is the uncertainty of the consequences of the current decision, and the other is the uncertainty of the future preference for these consequences (Simonson, 1989). An effective way for consumers to resolve these uncertainties related to decision-making is to choose a compromise option (Chang et al., 2012). Because the compromise option can minimize the maximum possible errors, it is the safest option (Simonson, 1989). According to Dhar and Simonson (2003), when consumers are uncertain about their preferences and have to make choice decisions, they tend to choose options with low regret probability, such as compromise options. Sheng et al. (2005) found that when consumers are in a high state of uncertainty, they are more likely to choose the compromise option, and the compromise effect they show is the result of minimizing the expected loss.

In addition, there is an extreme aversion to consumers. Extreme aversion means that if an option is in the middle of the option set, its attractiveness will be enhanced, while if it is an extreme option, its attractiveness will be reduced (Simonson \& Tversky, 1992). Based on the concept of loss aversion, Simonson and Tversky (1992) put forward the principle of extreme avoidance, and pointed out that the compromise effect of choosing an intermediate option can avoid selecting the extreme attribute value, thus reducing the risk. Sharpe et al. (2008) also found that when people buy soft drinks, their purchasing decisions are af- 
fected by the compromise effect due to extreme avoidance and insensitivity to product price. In addition, the compromise effect is also based on consumers' aversion to loss, that is, consumers will take the loss more seriously than the gain. The compromise option has only a small loss and gain for the extreme option, so it is the most popular option (Simonson \& Tversky, 1992).

\subsection{The Perspective of Rational Decision-Making}

In general, the compromise effect is considered to be a deviation from rationality in choice and a subversion of rational choice theory. However, some scholars think that the compromise effect is the rational inference made by consumers based on market data. Wernerfelt (1995) assumed the premise of complete rationality and believed that the compromise effect was a manifestation of consumers' use of commodity information provided by the market to predict the utility. When decision makers know their relative preference but not their absolute preference, they will infer their correct choice from the product set in the market, and this hierarchical decision principle will lead to compromise effect.

\section{The Influencing Factors of the Compromise Effect}

In the past, some studies focused on the mechanism of the compromise effect, while others focused on the factors that strengthened or weakened the compromise effect. This chapter will sort out the influencing factors of the compromise effect.

\subsection{Consumer Factors}

1) Gender

When consumers make decisions together with others, i.e. in the joint binary decision, the gender of consumers and decision partners will affect the compromise effect. Nikolova and Lamberton (2016) found that in the mixed gender or dual female gender model, the preference of compromise choice would be repeated compared with that of single-gender decision-making, and when two men were making decisions, their tendency to choose compromise would be weakened. This is partly because two men making decisions together are maximally consistent with masculinity and prioritise male norms, so they are more likely to make extreme choices. On the other hand, men were more critical of the compromises made by male decision makers than by female decision makers, and therefore less likely to make compromises.

2) Confidence

The degree of consumer confidence affects the compromise effect. In the face of complex or uncertain decisions, confidence can withstand market pressure (Bearden et al., 2001). Chuang et al. (2013) found that consumers with low confidence are more likely to make compromise choices due to their high decision-making uncertainty. In contrast, highly confident individuals make purchase decisions with less uncertainty and are less likely to make compromises. 
Chang et al. (2012) also found that consumers are more likely to choose the compromise option when making choices for others than when making choices for themselves, mainly because consumers are faced with greater uncertainty when making choices for others, which reduces decision-making confidence. Other scholars pointed out that the higher the confidence of consumers' preference, the less likely they would choose the compromise option (Yang et al., 2018).

3) Uniqueness needs

Simonson \& Nowlis (2000) believed that when decision-makers have a strong demand for uniqueness, they are less likely to choose the compromise option or the conventional option. They believed that consumers' demand for uniqueness will weaken the compromise effect. In addition, Kim and Kim (2016) also found that when consumers are in the hedonic consumption situation, the compromise effect will be weakened. Because consumers pay attention to enjoyment and pleasure in hedonic consumption, and pay attention to individual unique needs, they tend to extreme rather than intermediate options.

4) Risk appetite

According to the formation mechanism of the compromise effect, the compromise effect shows a tendency of loss avoidance. Therefore, consumers' own risk appetite will also affect the compromise effect. Mourali et al. (2007) believe that loss-avoiding consumers are more susceptible to the compromise effect than profit-oriented consumers. Loss-avoiding consumers are individuals who pay more attention to safety and protection, so they are more conservative and cautious in making decisions. They tend to reduce risks and avoid mistakes when making choices, so they are willing to choose products that are well-behaved in every attribute. However, the profit-oriented consumers are individuals who pay more attention to achievement and progress, so they prefer the extreme options that are outstanding in some attributes when making decisions, and they expect to get better achievements and results by choosing the extreme options. Liu et al. (2016) found that for the profit-oriented consumers, the acquisitive promotion description can reduce their preference for the compromise option, while for the loss-avoiding consumers, a loss-reducing promotion description can make them less likely to choose the compromise option.

5) Perceived the relationship between price and quality

People often say that "you get what you pay for", this kind of evaluation standard actually represents a kind of "price-quality" two-dimensional evaluation model. The perceived price quality relationship of consumers will also affect the degree of compromise effect. In the study of Li et al. (2012), they found that in the context of online shopping, when consumers perceive a high relationship between price and quality, the degree of compromise effect will increase; otherwise, the degree of compromise effect will decrease. For consumers who perceive a high relationship between price and quality, the influence weight of quality in 
the evaluation process will be greater, and the balance between price and quality will be more necessary, thus leading to a stronger compromise effect. On the other hand, consumers with a low relationship between perceived price and quality will think that their quality is similar or the same, and will prefer the option of lower price, so it is not easy to produce a compromise effect.

6) Familiarity with the product

Through research, scholars have found that consumers' familiarity with products is an important factor affecting the compromise effect. Mishra et al. (1993) found that when consumers have rich product knowledge or are very familiar with products, their choice decisions are less influenced by the compromise effect. Because when consumers have more product knowledge, they will follow the principle of value maximization more in the selection process. Sheng et al. (2005) showed that the more familiar consumers are with the products they want to buy, the less likely they are to choose the compromise option. Chen et al. (2008) believed that the more familiar consumers are with the product, the easier it is to extract information from the shopping environment and memory, and make a more comprehensive evaluation of the target options, thus weakening the compromise effect.

7) Decision object

Chang et al. (2012) found that the compromise effect is stronger when consumers make choices for others than for themselves. When consumers choose for those close to them, the compromise effect is weakened. Conversely, a lower level of intimacy leads to greater uncertainty about the preferences of others and a greater need for justification, so the compromise effect is enhanced. In addition, expected regret also moderates the impact of the decision object (the other person/self) on the compromise effect. People who make choices for others in anticipation of regret are more likely to choose the middle option than those who don't. Cox (1967) proposed that risk consists of negative consequences and uncertainty. When consumers make choices for others in anticipation of regret, they are more uncertain and afraid of making wrong decisions, so the compromise effect is more significant.

\subsection{Product Factors}

1) Country of origin

Consumers' attitudes towards certain countries can directly affect their product selection bias. Chuang et al. (2007) pointed out that when consumers have a negative impression of product origin, the compromise effect will decrease.

\section{2) Product type}

Mishra et al. (1993) pointed out that for convenience products, consumers are more likely to be influenced by the environment when making purchase decisions due to their lower preference intensity differences, thus showing a strong compromise effect. The concept opposite to convenience products is shopping goods. The alternatives of shopping goods are with higher prices and are more 
different from each other. Therefore, consumers are eager to reduce consumption risks and make more satisfying purchase decisions by knowing more product knowledge. As consumers have a clear preference for alternative goods after learning before purchase decision, they are not easily affected by the environment in the process of purchase decision, which may show a weak compromise effect. In addition, Kim and Kim (2016) found that practical consumption had a stronger compromise effect than hedonic consumption. This is because when people consume practical products, they focus on practicality and functionality, and use valuation processes when making choices. While when people consume hedonic products, they will focus on enjoyment and pleasure, and rely more on emotion when making choices. Thus, in the context of hedonic consumption, consumers prefer to choose extreme options.

3) Brand

LI Dong-jin et al. (2012) pointed out that when consumers are faced with options with different prices but identical other information, most consumers prefer the option with the lowest price if the option is a brand product, thus inhibiting the compromise effect. If the option is a non-brand product, the compromise effect will be enhanced. Sinn et al. (2007) studied the moderating effect of product brands on the compromise effect. When consumers are not familiar with the brand of compromise options, they tend to choose the brand of extreme options.

\subsection{Selection Factors}

1) Information presentation.

In the selection set, the presentation of the information of each selection attribute will affect the degree of the compromise effect. Chang and Liu (2010) believe that the more the products in the standby set are displayed together, the more the product attributes are displayed by matrix, and the closer the neutral option is to the middle, the greater the compromise effect will be. Kim (2017) found that compared with the numerical presentation, the compromise effect was more significant in the graphical information presentation. This is because the graphical information is rendered in a way that helps individuals observe the relationships between attributes, thus making it easier for them to identify the relative positions of compromise options. Guo (2013) pointed out that the mode of information prompt has a main effect on the compromise effect, and the one-sided prompt is more likely to promote the compromise effect than the two-sided prompt. This is because the two-sided negative prompt causes the risk cognition of two opposite directions to cancel each other, and weakens the individual's risk aversion behavior, which makes it unnecessary for the individual to choose the "middle term", resulting in a small compromise effect. However, in the research of Li et al. (2012), when the option with higher price is added in the network context, it can significantly change consumers' preference for the original two options, resulting in a compromise effect. However, this change cannot 
be realized when the option with lower price is added. This may be because consumers expect to pay lower prices in the online environment, making low-price options more attractive than high-price options.

2) Whether the importance of attributes is symmetrical

Sheng et al. (2005) found that the more asymmetrical the importance of the two attributes selected, the less consumers would choose the compromise item. This is because when the importance of attributes is symmetrical, consumers are faced with a relatively difficult decision. Extreme options have advantages in one attribute, but this advantage is offset by disadvantages in another attribute. At this point, the likelihood of choosing a compromise increases. On the contrary, when the two attributes are asymmetrical in importance, such as a selected product's outstanding performance in an important attribute, the attractiveness of the product will correspondingly increase, while the attractiveness of other options will decrease, thus weakening the compromise effect.

\subsection{Decision Environment Factors}

1) Time pressure

Dhar et al. (2000) studied the influence of time pressure as a moderating variable on the compromise effect, and the results showed that the shorter the time, the lower the probability of the compromise effect. Lin et al. (2008) investigated the influence of time pressure on the compromise effect. They found that when consumers were under greater time pressure, the likelihood of a compromise was lower. Because in time-constrained situations, consumers are more likely to adopt non-compensatory decision principles.

2) Task difficulty

Lee et al. (2016) demonstrated through four experiments that when task selection became more difficult, the compromise effect was weakened. According to the resource-matching hypothesis, tasks become more difficult for decision makers when the available cognitive resources cannot match the required cognitive resources. This difficulty leads them to use intuition rather than deliberation, thus weakening the compromise effect.

3) Decision interruption

Interruption has become a part of People's Daily life, and the phenomenon of interruption in the decision-making process will also have an impact on the decision-making behavior itself. Zhang et al. (2019) found that decision interruption can reduce consumers' preference for compromise options. This is because, when consumers experience the interrupt task and return to the original decision task, their understanding of the decision information before the interruption will trigger their sense of familiarity, improve their ability to take the decision risk, and thus increase their preference for extreme options.

\section{4) Leading information}

Chen et al. (2008) adopted the experimental method to study the compromise effect by introducing the inductive information. The experimental results found 
that consumers would still show the compromise effect when confronted with the inductive information. However, when the presentation mode of induced information is changed, specifically, consumers are allowed to make their own choices in the neutral information environment first and then the induced information is presented, and the final result shows that the compromise effect is weakened. This is because consumers form self-reference after the first independent choice, and when they are subsequently confronted with high or low price inductive information, the option pointed to by the inductive information becomes the most popular option.

5) Marketing strategy.

Nowlis \& Simonson (2000) proposed that the effects of marketing strategies and situational effects on consumer choice are complementary, and the results show that when merchants offer price promotion for low-priced goods, the compromise effect of consumers in product selection is weakened. Through research, Yan et al. (2012) also found that when consumers are faced with the purchase decisions of convenience products or shopping goods, the price marketing strategy will weaken the compromise effect. Among them, when consumers are faced with the purchase decisions of convenience products, the price marketing strategy weakens the compromise effect to a greater extent than that are faced with the purchase decisions of shopping goods. In addition, when consumers are faced with the purchase decisions of convenience products or shopping goods, the promotion strategy will weaken the compromise effect. Among them, when consumers are faced with the purchase decisions of convenience products, the degree of weakening of the promotion strategy to the compromise effect is greater than the degree of weakening of the promotion strategy to the compromise effect when consumers are faced with the purchase decision of shopping goods. For the purchase decisions of convenience products, the weakening degree of price marketing strategy to the compromise effect is greater than the weakening degree of promotion strategy to the compromise effect.

\section{Marketing Practice Enlightenment}

\subsection{Compromise Effect and Product Positioning}

The compromise effect widely exists in consumers' decision-making in real life. Therefore, marketers need to pay attention to the eclectic effect and adjust the product positioning to make their products more popular among consumers in the market. For example, if companies want consumers to buy more of their high-end products, they should only offer high-end and mid-range products. Because if there are high, medium and low grade products, there will always be a compromise effect. Even in the face of the leading information, consumers will still choose the middle grade products more than the two end products (Chen et al., 2011). In addition, in the real shopping environment, consumers often make purchase choices for others, such as buying souvenirs for relatives and helping others to buy things. But there are many choices in the market, and the choice 
settings often dazzle consumers. Based on the research results of Chang et al. (2012), consumers are more likely to produce compromise effect when making decisions for others than for themselves. So marketers can focus on developing average attributes when positioning new products, especially those that are often bought as gifts or souvenirs, to avoid making the product an extreme choice. In addition, the type of product can also affect the compromise effect. For example, the consumption of practical products has a more significant compromise effect than that of hedonic products (Kim \& Kim, 2016). Therefore, for practical products, marketers should provide customers with intermediate options; for hedonistic products, marketers should offer consumers extreme options.

\subsection{Compromise Effect and Marketing Strategy}

Marketers can combine the compromise effect to develop a more effective marketing strategy. For example, for the purchase of convenience products, the weakening degree of price marketing strategy to the compromise effect is greater than the weakening degree of promotion strategy to the compromise effect (Yan et al., 2012). Therefore, merchants should increase the frequency and intensity of price strategy for convenience products' sales. For example, when consumers are faced with leading information, they will still show the compromise effect. However, if consumers are allowed to make choices independently in the neutral information environment before presenting the induced information, consumers will form a self-reference, which will weaken the compromise effect (Chen et al., 2008). Therefore, when marketers want to sell high-priced products to consumers, they can first let customers make a clear choice without leading information, and then provide high-priced leading information to let customers make a new choice, thus weakening the impact of the compromise effect.

\subsection{Compromise Effect and Competitive Pattern}

The compromise effect subverts the rational choice theory. The compromise effect points out that adding a new choice to the existing selection will affect the individual's original selection preference. This is reflected in the market that the entry of a new product or competitor will change the market share and market fate of the original product or competitor (Guo, 2013). Therefore, managers need to pay attention to the emergence of new products and the changes in the competitive pattern caused by the compromise effect. For example, for non-brand products, the compromise effect is significant (Li et al., 2012). Therefore, managers of non-brand products should pay attention to the emergence of low-price products if their own pricing is high, and to the emergence of high-price products if their own pricing is low, so as to avoid the rapid erosion of the original market share due to the impact of the compromise effect. For brand products, consumers prefer the option of the lowest price, and the compromise effect is not significant (Li et al., 2012). Therefore, managers of branded 
products can attract consumers by offering low prices, such as "bundling" or promoting individual products to drive sales of other products.

\section{Future Research Direction and Prospect}

It has been 28 years since the compromise effect $t$ was published in 1989. The existing researches mainly focus on the formation mechanism and influencing factors of the compromise effect, but there are still research puzzles.

First of all, the research on the compromise effect in foreign countries is relatively complete, but the research on the compromise effect in China is still less. Whether the existing research results are applicable to China's national conditions still needs more research and discussion. For example, in the study of Chang et al. (2012), they found that interpersonal sensitivity can regulate the influence of decision objects (others/selves) on the compromise effect. Compared with Americans, Chinese people's behaviors and attitudes towards friends and strangers are more different. Chinese people give more to their friends than to strangers and show more cooperation to their friends than to strangers, while Americans' attitudes towards the two are not different. As a result, Chinese people exhibit higher interpersonal sensitivity, which may make the effect of relationship closeness on the compromise effect different. Future research can combine with existing research results to carry out cross-cultural research.

Secondly, with the booming development of e-commerce, there have been some researches on the compromise effect in the online shopping situation in the domestic academic circle. However, most of these studies focus on the influencing factors of the compromise effect without further discussion on its nature. Future research can further explore whether the compromise effect in online shopping situation is an extension or transfer from the compromise effect in traditional offline channels to the Internet channel, or whether it is a special phenomenon only in network context that is different from the eclectic effect in offline channels.

Finally, the existing researches focus more on the formation mechanism and influencing factors of the compromise effect, but not on the negative compromise effect. Future research can further explore the negative effects of the compromise effect.

\section{Major Contributions and Limitations}

Since 1989 when Simonson published his article on the compromise effect, there have been many researches on the compromise effect at home and abroad. However, there is a lack of systematic reviews on these researches on compromise effects at home and abroad. Therefore, the main contribution of this paper is to, on the basis of a comprehensive review of the literature related to the compromise effect, discuss the formation mechanism of the compromise effect, the influencing factors and the enlightenment of the compromise effect on the practice of commodity marketing, and point out the future research direction. This 
could help other researchers to further study the compromise effect.

However, this paper also has limitations. Many scholars at home and abroad have carried out the research on the compromise effect. Whether these research conclusions will be different due to different cultural backgrounds, this paper does not make further comparison and summary. Future research can be further summarized from the perspective of cross-cultural.

\section{Conflicts of Interest}

The author declares no conflicts of interest regarding the publication of this paper.

\section{References}

Bearden, W., Hardesty, D., \& Rose, R. (2001). Consumer Self-Confidence: Refinements in Conceptualization and Measurement. Journal of Consumer Research, 28, 121-134. https://doi.org/10.1086/321951

Chang, C. C., \& Liu, H. H. (2010). Information Format-Option Characteristics Compatibility and the Compromise Effect. Psychology \& Marketing, 25, 881-900. https://doi.org/10.1002/mar.20242

Chang, C. C., Chuang, S. C., Cheng, Y. H., \& Huang, T. Y. (2012). The Compromise Effect in Choosing for Others. Journal of Behavioral Decision Making, 25, 109-122. https://doi.org/10.1002/bdm.720

Chen, J. S., Fu, G. Q., \& Wu, J. T. (2011). When Could Persuasive Information Influence Consumer's Choice? Chinese Journal of Management, 8, 437-474.

Chuang, S. C., Cheng, Y. H., Chang, C. J., \& Chiang, Y. T. (2013). The Impact of Self-Confidence on the Compromise Effect. International Journal of Psychology, 48, 660-675. https://doi.org/10.1080/00207594.2012.666553

Chuang, S. C., Kao, D. T., Wu, P. H. et al. (2007). Aspiration and Compromise Effect. Psychological Reports, 101, 1179-1188.

https://doi.org/10.2466/pr0.101.4.1179-1188

Cox, D. E. (1967). Risk Taking and Information Handling in Consumer Behavior. Boston, MA: Harvard University Press.

Dhar, R., \& Glazer, R.. (1996). Similarity in Context: Cognitive Representation and Violation of Preference and Perceptual Invariance in Consumer Choice. Organizational Behavior \& Human Decision Processes, 67, 280-293. https://doi.org/10.1006/obhd.1996.0080

Dhar, R., \& Sherman, N. S. J. (2000). Trying Hard or Hardly Trying: An Analysis of Context Effects in Choice. Journal of Consumer Psychology, 9, 189-200. https://doi.org/10.1207/S15327663JCP0904 1

Dhar, R., \& Simonson, I. (2003). The Effect of Forced Choice on Choice. Journal of Marketing Research, 40, 146-160. https://doi.org/10.1509/jmkr.40.2.146.19229

Guo, J. H. (2013). The Integrating Mechanisms of Compromise Effect. Journal of Psychological Science, 36, 434-439.

He, D. A. (2005). A Behavioral Analysis of the Transformation from Rational Choice to Irrational Choice. Economic Research Journal, No. 8, 73-83.

Huber, J., \& Puto, C. (1983). Market Boundaries and Product Choice: Illustrating Attraction and Substitution Effects. Journal of Consumer Research, 10, 31-44. 
https://doi.org/10.1086/208943

Huber, J., Payne, J. W., \& Puto, C. (1982). Adding Asymmetrically Dominated Alternatives: Violations of Regularity and the Similarity Hypothesis. Journal of Consumer Research, 9, 90-98. https://doi.org/10.1086/208899

Kim, J. (2017). The Influence of Graphical versus Numerical Information Representation Modes on the Compromise Effect. Marketing Letters, 28, 397-409. https://doi.org/10.1007/s11002-017-9419-4

Kim, S., \& Kim, J. (2016). The Influence of Hedonic versus Utilitarian Consumption Situations on the Compromise Effect. Marketing Letters, 27, 387-401. https://doi.org/10.1007/s11002-014-9331-0

Lee, C. F., Chuang, S. C., Chiu, C. K. et al. (2016).The Influence of Task Difficulty on Context Effect-Compromise and Attraction Effects. Current Psychology, 36, 1-18. https://doi.org/10.1007/s12144-016-9428-0

Li, D. J., Li, Y., \& Wu, R. J. (2012). A Study of the Influence of Product Price Information on Compromise Effects in Online Shopping. Contemporary Finance \& Economics, No. 11, 67-79.

Lichters, M., Brunnlieb, C., Nave, G. et al. (2016). The Influence of Serotonin Deficiency on Choice Deferral and the Compromise Effect. Journal of Marketing Research, 53, 183-198. https://doi.org/10.1509/jmr.14.0482

Lin, C. H., Sun, Y. C., Chuang, S. C. et al. (2008). Time Pressure and the Compromise and Attraction Effects in Choice. Advances in Consumer Research, 2008, 348.

Liu H., Yang Z. Y., \& Feng, C. X. (2016). Research on the Influence of Promotion Description on the Compromise Effect of Consumer Choice. China Market, No. 5, 70-71.

Mishra, S., Umesh, U. N., \& Stem, D. E. (1993). Antecedents of the Attraction Effect: An Information Processing Perspective. Journal of Marketing Research, 30, 331-349. https://doi.org/10.1177/002224379303000305

Mourali, M., Böckenholt, U., \& Laroche, M. (2007). Compromise and Attraction Effects under Prevention and Promotion Motivations. Journal of Consumer Research, 34, 234-247. https://doi.org/10.1086/519151

Nikolova, H., \& Lamberton, C. (2016).Men and the Middle: Gender Differences in Dyadic Compromise Effects. Journal of Consumer Research, 43, ucw035. https://doi.org/10.1093/jcr/ucw035

Nowlis, S. M., \& Simonson, A. I. (2000). Sales Promotions and the Choice Context as Competing Influences on Consumer Decision Making. Journal of Consumer Psychology, 9, 1-16. https://doi.org/10.1207/s15327663jcp0901 1

Sharpe, K. M., Staelin, R., \& Huber, J. (2008). Using Extremeness Aversion to Fight Obesity: Policy Implications of Context Dependent Demand. Journal of Consumer Research, 35, 406-422. https://doi.org/10.1086/587631

Sheng, S., Parker, A. M., \& Nakamoto, K. (2005). Understanding the Mechanism and Determinants of Compromise Effects. Psychology and Marketing, 22, 591-609. https://doi.org/10.1002/mar.20075

Simonson, I. (1989). Choice Based on Reasons: The Case of Attraction and Compromise Effects. Journal of Consumer Research, 16, 158-174. https://doi.org/10.1086/209205

Simonson, I., \& Nowlis, S. M. (2000). The Role of Explanations and Need for Uniqueness in Consumer Decision Making: Unconventional Choices Based on Reasons. Research Papers, 27, 49-68. https://doi.org/10.1086/314308

Simonson, I., \& Tversky, A. (1992). Choice in Context: Trade-off Contrast and Extremeness Aversion. Journal of Marketing Research, 39, 281-292. 
https://doi.org/10.1177/002224379202900301

Sinn, F., Milberg, S. J., Epstein, L. D. et al. (2007). Compromising the Compromise Effect: Brands Matter. Marketing Letters, 18, 223-236. https://doi.org/10.1007/s11002-007-9019-9

Tversky, A., \& Simonson, I. (1993). Context-Dependent Preferences. Management Science, 39, 1179-1189. https://doi.org/10.1287/mnsc.39.10.1179

Wernerfelt, B. (1995). A Rational Reconstruction of the Compromise Effect: Using Market Data to Infer Utilities. Journal of Consumer Research, 21, 627-633. https://doi.org/10.1086/209423

Yan, J. Y., Guo, H. L., \& Ji, Y. (2012). The Impact of Marketing Strategy on Compromise Effect Based on the B2C Website. Management Review, 24, 28-36+59.

Yang, Y. K., Zhang, Q. C., \& Lai, T. H. (2018). Compromise Effect of Consumers' Decision-Making and Preference Derail. Finance \& Economics, No. 7, 109-120.

Zhang, C. H., Li, D. J., \& Fu, G. Q. (2019). Will Interruption Undermines the Compromise Effect in Consumer Choice-Making? From the Mediating Effect of Familiarity. Luojia Management Review, No. 1, 129-151.

Zhang, Q. C., Lu, D., \& Zhou, T. R. (2011). A Review of Literature on Context Effect in Customer Choice Behavior and Future Research Prospect. Soft Science, 25, 130-134. 